\title{
Pioglitazone does not improve insulin signaling in mice with GH over-expression
}

\author{
Adam Gesing ${ }^{1,2}$, Andrzej Bartke ${ }^{1}$ and Michal M Masternak ${ }^{3,4}$ \\ 1Department of Internal Medicine, Geriatrics Research, Southern Illinois University School of Medicine, \\ 801 North Rutledge Street, Room 4389, Springfield, Illinois 62794-9628, USA \\ ${ }^{2}$ Department of Oncological Endocrinology, Medical University of Lodz, Zeligowski Street, No 7/9, \\ 90-752 Lodz, Poland \\ ${ }^{3}$ Burnett School of Biomedical Sciences, College of Medicine, University of Central Florida, 6900 Lake Nona \\ Boulevard, Orlando, Florida 32827, USA \\ ${ }^{4}$ Institute of Human Genetics, Polish Academy of Sciences, Strzeszynska Street, No 32, 60-479 Poznan, Poland
}

\author{
Correspondence \\ should be addressed \\ to A Gesing \\ Emails \\ adges7@wp.pl; \\ adges7@yahoo.com
}

\begin{abstract}
Type 2 diabetes and obesity are very serious health problems in both developed and developing countries. An increased level of $\mathrm{GH}$ is known to promote insulin resistance. Transgenic ( $\mathrm{Tg}$ ) mice over-expressing bovine $\mathrm{GH}$ are short-living and characterized, among other traits, by hyperinsulinemia and increased insulin resistance in comparison with normal (N) mice. Pioglitazone (PIO) is a member of the thiazolidinediones - a group of insulinsensitizing drugs that are selective agonists of peroxisome proliferator-activated receptor gamma (PPAR $\gamma$ ). The aim of the study was to analyze the effects of PIO on the insulinsignaling pathway in $\mathrm{Tg}$ and $\mathrm{N}$ mice. Plasma levels of insulin and glucose as well as hepatic levels of proteins involved in insulin signaling were analyzed by ELISA or western blot methods. Treatment with PIO decreased plasma level of glucose in N mice only. Similarly, PIO increased insulin sensitivity (expressed as the relative insulin sensitivity index; RISI) only in N mice. In the liver, PIO decreased the phosphorylation of insulin receptor substrate-1 (IRS1) at a serine residue (Ser ${ }^{307}$-pS-IRS1), which inhibits insulin action, and had a tendency to increase tyrosine phosphorylation of IRS2 (Tyr-pY-IRS2) only in N mice but did not affect either of these parameters in Tg mice. Levels of total and phosphorylated mammalian target of rapamycin were increased in Tg mice. Moreover, the level of AKT2 was decreased by PIO in $\mathrm{N}$ mice only. In conclusion, the lack of improvement of insulin sensitivity in insulin-resistant Tg mice during PIO treatment indicates that chronically elevated GH levels can inhibit the beneficial effects of PIO on insulin signaling.
\end{abstract}
Key Words
- pioglitazone
- insulin signaling
- growth hormone
- transgenic mice

Journal of Endocrinology (2013) 219, 109-117

\section{Introduction}

Diabetes, obesity, and other non-communicable chronic diseases are very serious health problems in both developed and developing countries, leading to increased morbidity and premature mortality (Abegunde et al. 2007). Obesity per se constitutes one of the main causes of insulin resistance and type 2 diabetes. Importantly, growth hormone $(\mathrm{GH})$, which is a key regulator of growth and metabolism processes, may exert anti-insulinemic and diabetogenic actions. These effects are considered to be the key physiological effects of GH on carbohydrate and lipid 
metabolism (Davidson 1987). Increased GH levels are known to promote insulin resistance in humans and laboratory animals (Hansen et al. 1986, Kopchick et al. 1999, Bartke 2003, Wang et al. 2007). For this reason, we decided to use in our study transgenic ( $\mathrm{Tg}$ ) mice overexpressing bovine $\mathrm{GH}$ (bGH) with a sequence from the phosphoenolpyruvate carboxykinase (PEPCK) gene as a promoter (PEPCK-bGH mice). These giant mice are shortliving and characterized, among other traits, by increased postnatal growth and adult body weight, organomegaly, reduced adiposity, various symptoms of accelerated aging, early onset of age-related changes in cognitive function, decreased plasma adiponectin, increased plasma resistin and cholesterol, elevated levels of tumor necrosis factor $\alpha$ (TNF $\alpha$ ) and interleukin-6 (IL6) in adipocytes, hyperinsulinemia and increased insulin resistance (Bartke 2003, Wang et al. 2007), as well as depletion of very small embryonic-like stem cells from bone marrow (Kucia et al. 2013).

Pioglitazone (PIO) is an anti-diabetic drug that belongs to the thiazolidinedione (TZD) class - selective agonists of peroxisome proliferator-activated receptor gamma (PPAR $\gamma$ ), which constitute a very important group of insulin-sensitizing drugs. It can exert beneficial antioxidant and anti-proliferative effects (Elte \& Blickle 2007), as well as anti-tumor activity by inducing apoptosis, and may decrease the risk of cardiovascular events (Lincoff et al. 2007).

The aim of the study was to analyze the effects of PIO on the insulin-signaling pathway (hepatic levels of insulin receptor (IR), insulin receptor substrate-1 (IRS1) - total and phosphorylated at a serine(307) residue (Ser ${ }^{307}$-pS-IRS1) (phosphorylation that inhibits insulin action), IRS2 - phosphorylated at a tyrosine residue (Tyr-pY-IRS2)) in PEPCK-bGH Tg and normal mice. Moreover, plasma glucose and insulin levels were determined in these animals. Importantly, the influence of PIO on various components of the insulin-signaling pathway under chronically elevated GH levels has not yet been, to our knowledge, analyzed.

Additionally, hepatic total mammalian target of rapamycin (mTOR; FKBP12-rapamycin-associated protein, FRAP1), phosphorylated mTOR (mTOR-pY), and AKT2 levels were assessed. It is known that hormones (including insulin), growth factors, and other mitogens activate the PI3K/AKT/mTOR signaling cascade (Mamane et al. 2006). Furthermore, rapamycin - a natural macrolide - used in cancer therapy and as a immunosuppressant drug as well, which inhibits mTOR, may lead to increases in life span in various species (Bjedov et al. 2010, Anisimov et al. 2011,
Miller et al. 2011, Selman \& Partridge 2012, Wilkinson et al. 2012). Therefore, it was also of interest to assess the effects of PIO on mTOR signaling.

\section{Materials and methods}

\section{Animals and assessment of blood chemistry}

Approximately 6-month-old male mice over-expressing bGH (PEPCK-bGH; Tg) and age-matched normal (N) controls were randomly assigned to control or treatment groups. At the beginning of the study ('before treatment' groups), the mice were divided into four experimental groups: $\mathrm{N}$ (ten animals), normal assigned to PIO treatment (N-PIO) (ten animals), Tg (ten animals), and $\mathrm{Tg}$ assigned to PIO treatment (Tg-PIO) (ten animals). These group designations were used both before and after treatment, and thus, 'after treatment', N-PIO and Tg-PIO groups in which insulin, blood glucose, relative insulin sensitivity index (RISI), and adiponectin were assessed denote animals that had been receiving PIO treatment. Basal glucose, insulin and adiponectin levels, as well as RISI were measured at the start of the study. The RISI was calculated from the equation: 100/ /blood glucose level $X$ insulin level. Then, the PIO treatment $(20 \mathrm{mg} / \mathrm{kg}$ body weight per day for the period of 20 days) was started in groups: N-PIO and Tg-PIO. PIO was incorporated in baconflavored diet (pellets of modified LabDiet Laboratory Rodent Diet 5001 with $0.2 \%$ PIO; TestDiet, Richmond, IN, USA). Once-daily PIO-treated animals were provided with small piece of food containing drug $(0.5 \mathrm{~g}$ for $\mathrm{Tg}$ and $0.3 \mathrm{~g}$ for $\mathrm{N}$ animals, corresponding to $20 \mathrm{mg} \mathrm{PIO} / \mathrm{kg}$ of body weight on average per day). The mice in groups $\mathrm{N}$ and $\mathrm{Tg}$ (without PIO treatment) were fed unmodified Lab Diet 5001 chow (PMI Nutrition International, Richmond, IN, USA).

The PEPCK-bGH (Tg) mice were originally produced by microinjecting the bGH structural gene fused with the promoter of the rat Pepck gene into the pronuclei of fertilized mouse eggs (McGrane et al. 1988). The hemizygous $\mathrm{Tg}$ mice used in this study were produced by mating $\mathrm{Tg}$ males with normal $\mathrm{C} 57 \mathrm{BL} / 6 \times \mathrm{C} 3 \mathrm{H} \mathrm{F}_{1}$ hybrid females. The mice used in the study were housed under temperature- and light-controlled conditions $\left(22 \pm 2{ }^{\circ} \mathrm{C}\right.$, $12 \mathrm{~h}$ light: $12 \mathrm{~h}$ darkness cycle). At the end of the experiment, basal glucose, insulin and adiponectin levels, as well as RISI were measured once more (see below). Half of the animals from each experimental group were treated with insulin and the remaining animals were treated with saline before tissues were collected to assess stimulation of the

Published by Bioscientifica Ltd 
phosphorylation of IR and the downstream pathway of insulin action. All animal procedures were approved by the Laboratory Animal Care and Use Committee (LACUC) at the Southern Illinois University School of Medicine (Springfield, IL, USA). After 20 days of PIO treatment, the animals were fasted overnight and fasting glucose levels were measured in blood collected from the tail vein using OneTouch Ultra glucometer (Life Scan, Milpitas, CA, USA). Then, the animals were killed and plasma obtained from blood collected by cardiac puncture was used for assessment of insulin using Rat/Mouse Insulin ELISA kit (Linco Research, Inc., St Charles, MO, USA) following the manufacturer's protocols. Adiponectin levels were assayed using mouse adiponectin ELISA kit (Linco Research). Total amount of IR in liver was assayed using an IR (Total) Human ELISA kit (Invitrogen). The assessment of the abovementioned four parameters (glucose, insulin, adiponectin, and total IR), as well as RISI, was performed in all animals in each group (i.e., in ten mice per group). Phosphorylated IRS2 levels were assayed using PathScan Phospho-IRS-2 (panTyr) Sandwich ELISA kit (Cell Signaling Technology, Inc., Danvers, MA, USA). In this case, five animals per each subgroup (treated with saline or with insulin) were analyzed. Livers were rapidly collected, quickly frozen on dry ice, and stored at $-80^{\circ} \mathrm{C}$ until processed.

\section{Protein extraction and western blotting}

Total proteins were obtained from tissue homogenates. Approximately $100 \mathrm{mg}$ liver samples were homogenized in $1 \mathrm{ml}$ ice-cold T-PER Tissue Protein Extraction Reagent (Pierce Biotechnology, Rockford, IL, USA), with Protease Inhibitor Cocktail kit (Pierce Biotechnology), Phosphatase Inhibitor Cocktail 1 (Sigma-Aldrich), and Phosphatase Inhibitor Cocktail 2 (Sigma-Aldrich). After mixing, homogenates were centrifuged at $16000 \mathrm{~g}$ for $30 \mathrm{~min}$. Protein concentrations were assessed using Pierce bicinchoninic acid (BCA) Protein Assay kit (Pierce Biotechnology) in accordance with the manufacturer's protocol.

The western blot procedure was performed using the respective primary antibodies: total IRS1, phospho-IRS-1 (Ser307), total mTOR, phospho-mTOR (Ser2448), Akt2 (all from Cell Signaling Technology, Inc.), and secondary goat anti-rabbit or anti-mouse antibodies (Calbiochem, La Jolla, CA, USA). Monoclonal anti- $\beta$-actin antibody (Sigma-Aldrich Corp.) was used, after stripping the membrane, as a control for protein loading.

Western blotting analysis was performed according to the method described previously (Gesing et al. 2011), and six animals per group were analyzed. Photos of blots were taken with Image Reader LAS-4000 (FujiFilm, Tokyo, Japan) and quantified for statistical analysis using GeneTools software (SynGene, Cambridge, UK).

\section{Statistical analysis}

The data are expressed as mean \pm s.E.M. To evaluate the effects of the genotype and pharmacological intervention, two-way ANOVA was used. Additionally, we used the Bonferroni test - post hoc test for analyzing differences between group means. A value of $P<0.05$ was considered significant. All statistical calculations were conducted using SPSS version 17.0 (SPSS) with $\alpha=0.05$. All graphs were made using Prism 4.02 (GraphPad Software, San Diego, CA, USA).

\section{Results}

Before PIO treatment, plasma insulin level was increased in Tg mice, when compared with $\mathrm{N}$ animals $(P=0.049$; Fig. 1A). After the treatment period, no changes between these two kinds of animals, not treated with PIO, were detected, although the overall effect of genotype (i.e., between pooled $\mathrm{N}$ and N-PIO mice and pooled Tg and Tg-PIO animals) was statistically significant with higher insulin levels in pooled Tg and Tg-PIO mice $(P=0.022$; Fig. 1B). The PIO treatment decreased the plasma level of glucose in $\mathrm{N}$ mice only $(P=0.048)$, with no effects in $\mathrm{Tg}$ animals (Fig. 1D). Before PIO treatment, no changes in blood glucose between $\mathrm{N}$ and $\mathrm{Tg}$ mice were observed (Fig. 1C). Similarly, no differences between these two experimental groups, not treated with PIO, were seen after the treatment period (Fig. 1D). Expectedly, insulin sensitivity (as indicated by the RISI) was decreased in $\mathrm{Tg}$ mice (pooled $\mathrm{Tg}$ and Tg-PIO) when compared with $\mathrm{N}$ animals (pooled $\mathrm{N}$ and N-PIO) $(P=0.012$; Fig. $2 \mathrm{~A})$. The RISI indicated that $\mathrm{PIO}$ increased insulin sensitivity in $\mathrm{N}$ mice only ( $P=0.033$; Fig. $2 \mathrm{~B}$ ). Before PIO treatment, the plasma adiponectin level was decreased in $\mathrm{Tg}$ mice, when compared with $\mathrm{N}$ animals $(P=0.0001$; Fig. $3 \mathrm{~A})$ ). A similar pattern was observed after the treatment period $(P=0.043$; Fig. 3B). The PIO treatment increased adiponectin level in plasma in $\mathrm{N}$ mice $(P=0.003)$, as well as in Tg animals, although approaching only borderline significance $(P=0.053$; Fig. 3B). No effects of PIO treatment on total IR level in the liver in $\mathrm{N}$ or $\mathrm{Tg}$ mice were detected (Fig. 4A). Importantly, the level of total IR was decreased in Tg mice in comparison with $\mathrm{N}$ animals $(P=0.009$; Fig. $4 \mathrm{~A})$. In the liver, PIO did not change the phosphorylation of Tyr-pYIRS2 (although it had a tendency to increase this

Published by Bioscientifica Ltd 

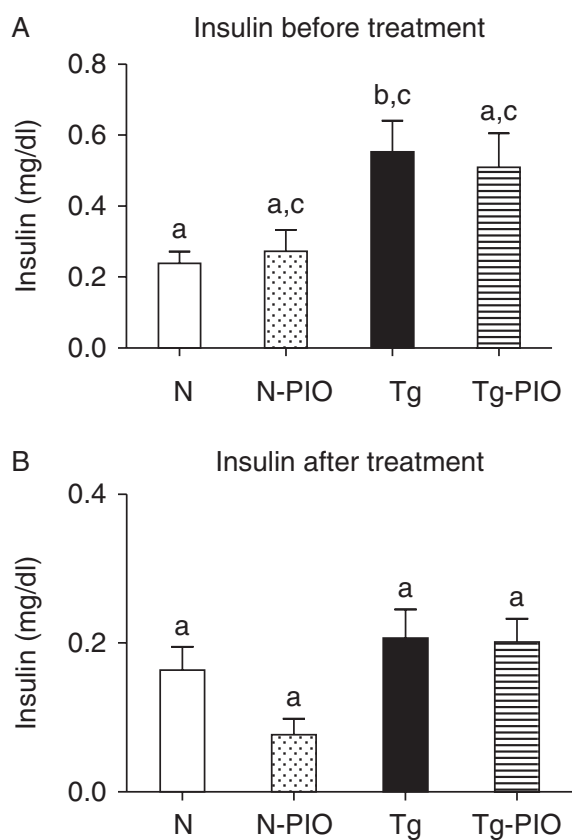

C Blood glucose before treatment

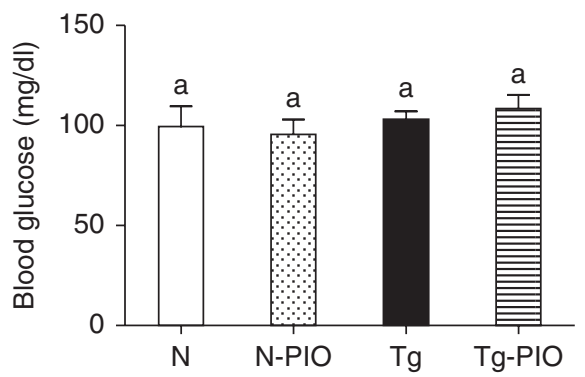

D Blood glucose after treatment

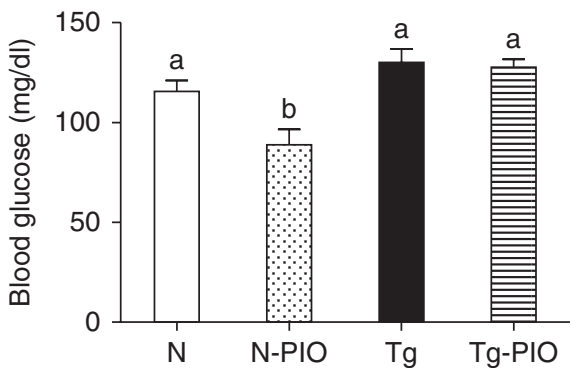

Figure 1

Plasma insulin level ( $\mathrm{mg} / \mathrm{dl})$ before $(\mathrm{A})$ and after (B) pioglitazone (PIO) treatment and blood glucose level ( $\mathrm{mg} / \mathrm{dl}$ ) before (C) and after (D) PIO treatment in normal $(\mathrm{N})$, and transgenic mice over-expressing bovine growth hormone $(\mathrm{Tg})$. Values are means \pm s.E.M. ${ }^{\mathrm{a}, \mathrm{b}, \mathrm{c}}$ Values that do not share the same letter in the superscript are significantly different $(P<0.05)$.

parameter in $\mathrm{N}$ mice), but decreased the $\mathrm{Ser}^{307}$-pS-IRS1, the phosphorylation that inhibits insulin action, in $\mathrm{N}$ mice $(P=0.0001)$ with no effects on either of these parameters in Tg mice (Fig. $4 \mathrm{~B}$ and $\mathrm{D}$ respectively). No changes in Tyr-pY-IRS2 level in $\mathrm{N}$ mice (without PIO treatment) treated with saline when compared with $\mathrm{N}$ animals treated with insulin were detected (Fig. 4B). Similarly, in Tg mice (without and after PIO treatment), there were no differences between saline- and insulintreated subgroups (Fig. 4B). Interestingly, PIO decreased total IRS1 level in livers of $\mathrm{N}$ mice $(P=0.003$; Fig. 4C). Furthermore, an increasing tendency of this parameter in PIO-treated Tg mice has been shown ( $P=0.14$; Fig. $4 \mathrm{C})$. No differences in total mTOR level between $\mathrm{N}$ and N-PIO, as well as between $\mathrm{Tg}$ and Tg-PIO mice, were observed (Fig. 5A). However, the level of mTOR was increased in Tg mice (pooled Tg and Tg-PIO) when compared with $\mathrm{N}$ animals (pooled N and N-PIO) $(P=0.0001$; Fig. $5 \mathrm{~A})$. Similar to total mTOR, phosphorylated mTOR protein level was also increased in $\mathrm{Tg}$ mice (pooled $\mathrm{Tg}$ and $\mathrm{Tg}$-PIO) in comparison with $\mathrm{N}$ animals (pooled $\mathrm{N}$ and N-PIO) $(P=0.001$; Fig. 5B). Additionally, PIO decreased hepatic AKT2 level in $\mathrm{N}$ mice $(P=0.011)$, with no effects observed in Tg mice (Fig. 5C).
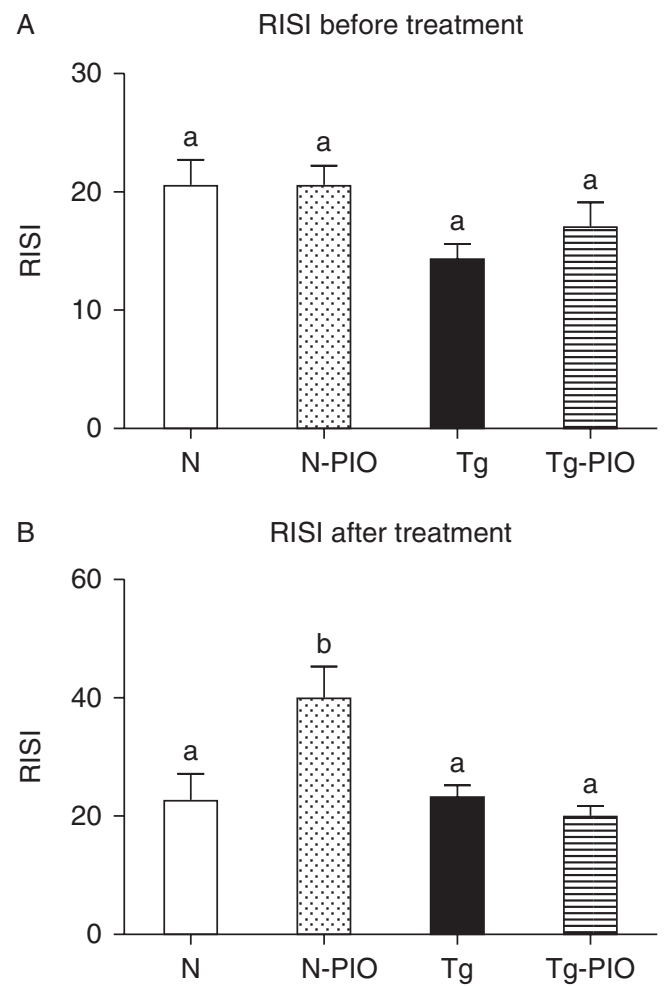

Figure 2

The relative insulin sensitivity index (RISI) $(100 / \sqrt{ }$ blood glucose level $\times$ insulin level) before (A) and after (B) pioglitazone (PIO) treatment in normal $(\mathrm{N})$ and transgenic mice over-expressing bovine growth hormone (Tg). Values are means \pm S.E.M. ${ }^{\text {a,b}}$ Values that do not share the same letter in the superscript are significantly different $(P<0.05)$. 
A Adiponectin before treatment

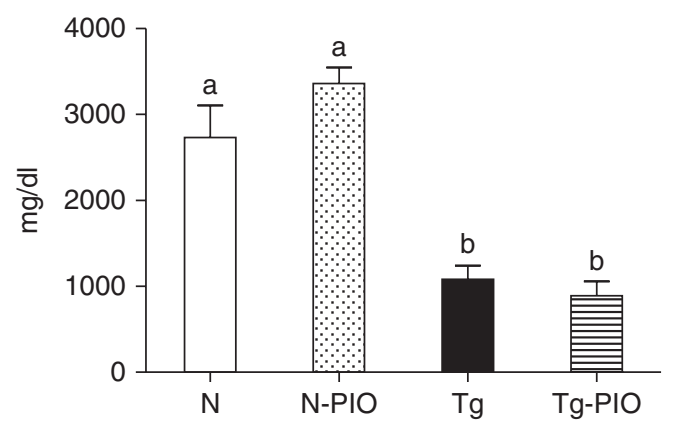

B

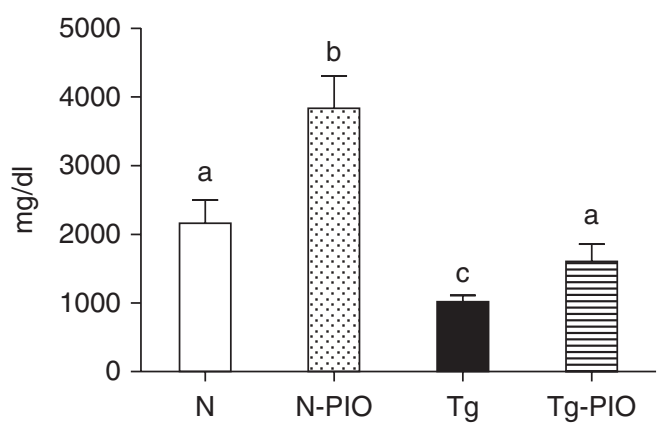

Figure 3

Plasma adiponectin level ( $\mathrm{mg} / \mathrm{dl}$ ) before (A) and after (B) pioglitazone (PIO) treatment in normal $(\mathrm{N})$ and transgenic mice over-expressing bovine growth hormone $(\mathrm{Tg})$. Values are means \pm s.E.M. ${ }^{\mathrm{a}, \mathrm{b}, \mathrm{c}}$ Values that do not share the same letter in the superscript are significantly different $(P<0.05)$.

\section{Discussion}

Insulin resistance is a very serious health problem, which may lead to diabetes and obesity. One should emphasize that elevated $\mathrm{GH}$ as well as insulin-like growth factor 1 (IGF1) may lead to higher risk of mortality (Holdaway et al. 2004). Tg mice over-expressing GH are characterized, among other traits, by hyperinsulinemia and increased insulin resistance (Wang et al. 2007). Therefore, PEPCKbGH mice constitute an excellent model system for studies of the control of insulin sensitivity and insulin resistance during anti-diabetic treatment.

Krag et al. (2009) have shown that one of the mechanisms that may be responsible for improvement of insulin sensitivity due to PIO treatment is the decrease in pro-inflammatory IL6 level. IL6 is a cytokine, produced in adipose tissue (Fried et al. 1998), as well as in skeletal muscles, being one of the important myokines (Pedersen $\&$ Febbraio 2008), involved in the regulation of insulin sensitivity. It has been previously reported that IL6 may inhibit the insulin-signaling pathway by upregulation of suppressors of cytokine signaling-3 (SOCS3) - a marker of the activation of IL6 signaling (reviewed in Coelho et al. (2013)). In turn, SOCS3, as well as SOCS1, may lead among other effects - to impaired IRS1 and IRS2 tyrosine phosphorylation. Interestingly, Wan et al. (2012a) have shown that IL6 may be involved in the regulation of mitochondrial function in adipose tissue, being an activator of AMP-activated protein kinase - one of the key regulators of mitochondrial biogenesis. However, recent data have revealed that the cytokine in question is not necessary for regulation of mitochondrial content in adipose tissue (Wan et al. 2012b). Nevertheless, there is a growing amount of data showing a dual role of IL6 in the regulation of insulin sensitivity (e.g., Jiang et al. 2013).

The mechanisms of action of PIO, relying on the decrease in plasma levels of glucose, and the increase in the RISI in N mice only, as seen in our study, are consistent with the well-known insulin-sensitizing properties of this drug. Puddu et al. (2012) have recently shown that PIO protects pancreatic islet cells (line HIT-T15) from the detrimental effects of advanced glycation end-products (AGEs). Moreover, PIO is an effective drug in lowering HbA1c (Russell-Jones et al. 2012).

One should recall that TZDs may decrease GH and IGF1 synthesis and levels, and, as a consequence of this, attenuate anti-insulin activity (exerted by $\mathrm{GH}$ ), which may lead to the improvement of the insulinsignaling pathway. Intriguingly, the doses of PIO, commonly used in the treatment of type 2 diabetes, did not improve GH and IGF1 levels in acromegalic patients (characterized by impaired insulin sensitivity) (Kim et al. 2012). These observations may be considered as consistent with our results showing lack of a beneficial effect of PIO treatment in Tg mice. Nevertheless, it seems that the role of the interactions between GH and PIO requires further analyses.

The effects of PIO, leading to increased plasma adiponectin levels in $\mathrm{N}$ mice, agree with the results of the studies by $\mathrm{Yu}$ et al. (2002), showing increased adiponectin levels after treatment with TZDs. PIO also increased serum adiponectin levels in 8-week highfructose-diet-fed rats (Schaalan 2012) and in obese men (Powell et al. 2012). Adiponectin level was also increased in Wistar rats, fed a high-fat insulin-resistance-inducing diet, treated with PIO (Gong et al. 2012). Moreover, PIO treatment in these animals, fed a diet inducing derangements in the insulin-signaling pathway, led to increased levels of adiponectin receptor type 2 and to decreased insulin resistance (Gong et al. 2012). The increase in adiponectin levels in Tg mice, as a result of PIO treatment, seems, to some degree, to be consistent with the results of

Published by Bioscientifica Ltd 
A

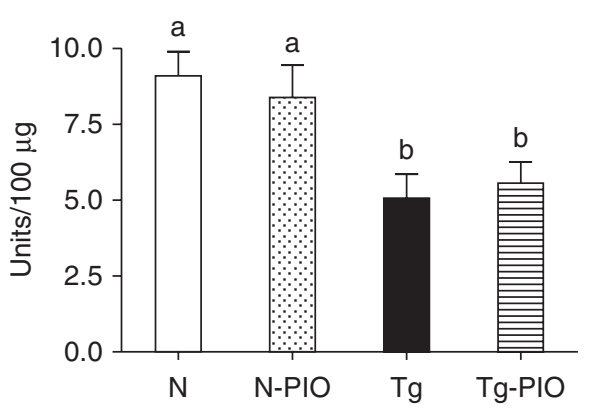

C

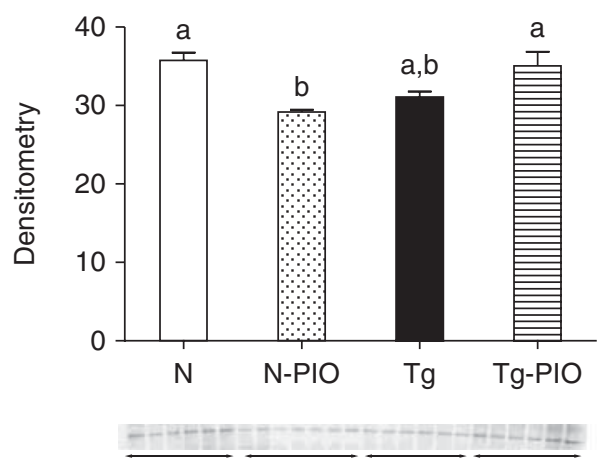

B

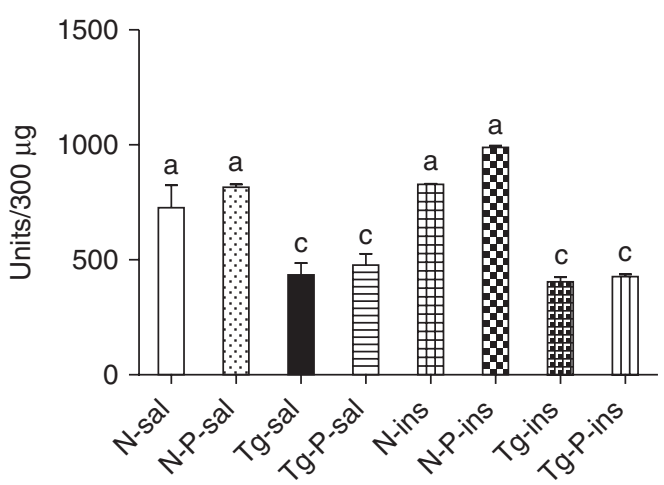

D

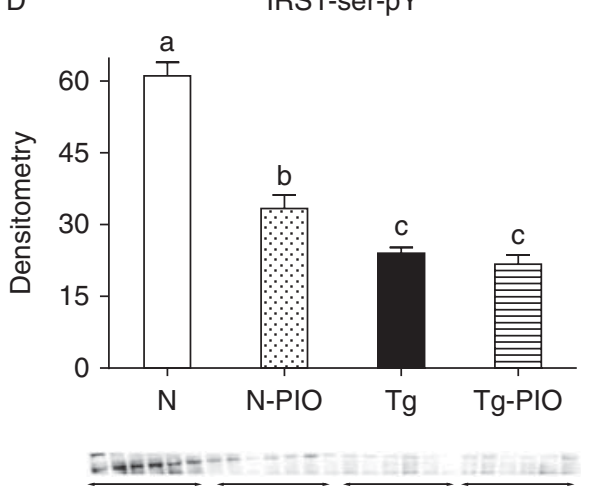

\section{Figure 4}

(A) Hepatic total insulin receptor (IR) protein level (units/100 $\mu$ g protein) in normal $(\mathrm{N})$ and transgenic mice over-expressing bovine growth hormone ( $\mathrm{Tg}$ ) without pioglitazone (PIO) treatment and after PIO treatment in normal (N-PIO) and transgenic mice over-expressing bovine growth hormone (Tg-PIO); (B) hepatic insulin receptor substrate-2 (IRS2) phosphorylated at a tyrosine residue (IRS2-T pY) protein level (units/300 $\mu \mathrm{g}$ protein) in $\mathrm{N}$ mice treated with saline ( $\mathrm{N}$-sal) or insulin ( $\mathrm{N}$-ins) and Tg mice treated with saline (Tg-sal) or insulin (Tg-ins) without PIO treatment, and after PIO treatment in N mice treated with saline (N-P-sal) or insulin

the study performed by Krag et al. (2008), showing increased adiponectin levels in GH-deficient patients with GH replacement therapy, receiving PIO treatment. Concerning the well-known anti-atherogenic properties of adiponectin, one should also recall the data of Saremi et al. (2013), who have recently reported that PIO may retard atherosclerosis progression in people with prediabetes. Interestingly, adiponectin-deficient mice are unresponsive to the anti-diabetic effects of TZDs (Nawrocki et al. 2006). Furthermore, the suppressive effects of PIO on angiotensin II-induced cardiac hypertrophy, as were seen in wild-type mice, were diminished in adiponectin-deficient mice ( $\mathrm{Li}$ et al. 2010).

Decreased phosphorylation of IRS1 (Ser ${ }^{307}$-pS-IRS1) in the liver due to PIO treatment in $\mathrm{N}$ mice constitutes beneficial effect of this drug because that kind of
(N-P-ins) and Tg mice treated with saline (Tg-P-sal) or insulin (Tg-P-ins); (C) hepatic total IRS1 protein level (using primary antibody from Cell Signaling Technology, Inc.) in N and Tg mice without PIO treatment, and after PIO treatment in N (N-PIO) and Tg mice (Tg-PIO), (D) hepatic IRS1 phosphorylated at a serine(307) residue (IRS1-ser-pY) protein level (using primary antibody from Cell Signaling Technology, Inc.) in $\mathrm{N}$ and Tg mice without PIO treatment and after PIO treatment in N (N-PIO) and Tg mice

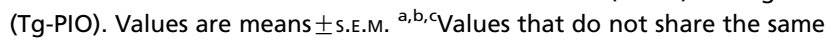
letter in the superscript are significantly different $(P<0.05)$.

phosphorylation leads to inhibition of insulin action. Also, a tendency to increase phosphorylation of IRS2 (TyrpY-IRS2) in $\mathrm{N}$ animals seems to be beneficial for proper insulin signaling as it is known that the opposite situation, i.e., inhibition of tyrosine phosphorylation of IRS proteins, caused by SOCS1 and SOCS3, may lead to insulin resistance (Ueki et al. 2004). Importantly, PIO may improve insulin sensitivity through the suppression of SOCS3 (Kanatani et al. 2007). Interestingly, SOCS1 knockout mice are characterized by increased liver IRS2 expression and IRS2 tyrosine phosphorylation that may lead to enhanced hepatic insulin sensitivity (Jamieson et al. 2005).

The unexpected numerical (although not statistically significant) increase in total IRS1 level in the liver in Tg mice, potentially leading to the improvement of insulin signaling, and decrease in this substrate in the same organ 


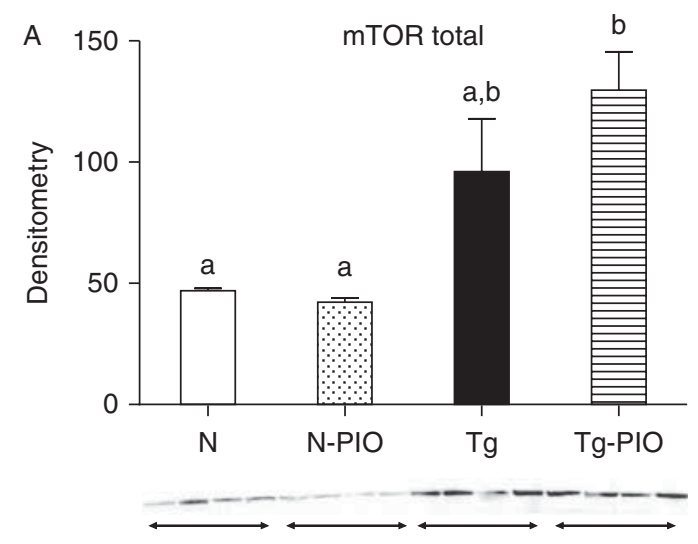

B

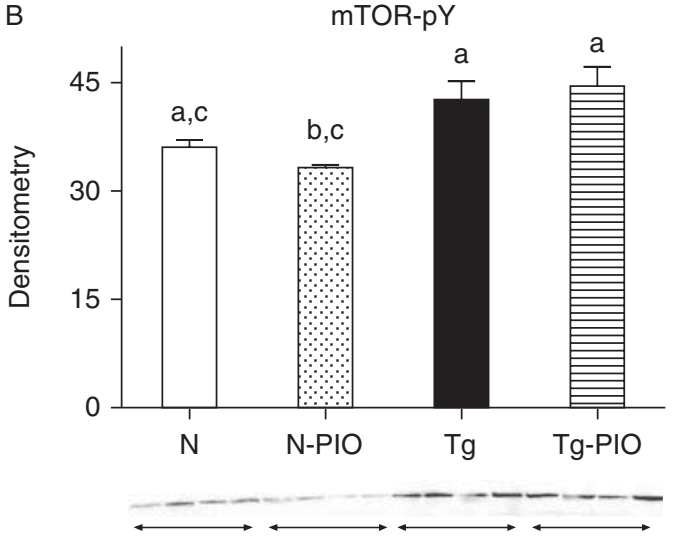

C

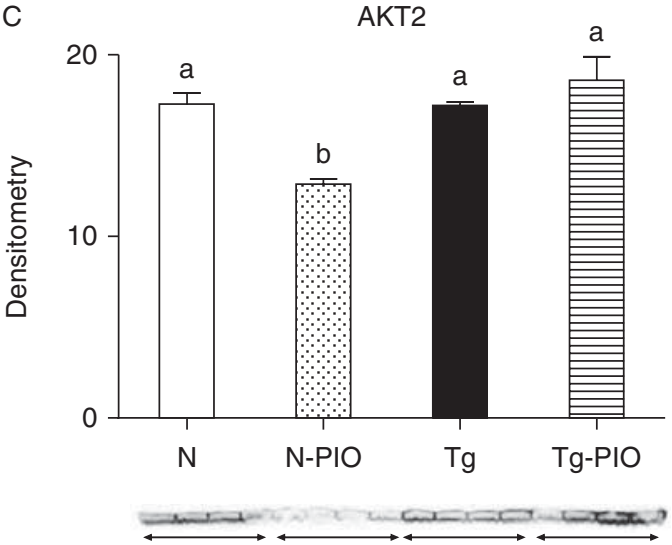

Figure 5

(A) Hepatic total mTOR protein level (using primary antibody from Cell Signaling Technology, Inc.) in normal (N) and transgenic mice over-expressing bovine growth hormone $(\mathrm{Tg})$ without pioglitazone (PIO) treatment and after $\mathrm{PIO}$ treatment in normal (N-PIO) and transgenic mice over-expressing bovine growth hormone (Tg-PIO); (B) hepatic mTOR phosphorylated at a tyrosine residue (mTOR-pY) protein level (using primary antibody from Cell Signaling Technology, Inc.) in $\mathrm{N}$ and Tg mice without PIO treatment and after PIO treatment in N (N-PIO) and Tg mice (Tg-PIO); (C) hepatic AKT2 protein level (using primary antibody from Cell Signaling Technology, Inc.) in N and Tg mice without PIO treatment and after PIO treatment in N (N-PIO) and Tg mice (Tg-PIO). Values are means \pm s.E.M. ${ }^{a, b}, \mathrm{c} V$ alues that do not share the same letter in the superscript are significantly different $(P<0.05)$. in N mice, due to PIO treatment, seems to be quite difficult to interpret. However, Taniguchi et al. (2006) have shown that liver-specific deletion of the $\mathrm{p} 85 \alpha$ regulatory subunit of PI3K, constituting the next downstream step (after IRS1) in the insulin signaling pathway, may paradoxically improve the hepatic and peripheral insulin sensitivity. Importantly, the decreased level of total IR in Tg mice in comparison with $\mathrm{N}$ animals may be considered to be consistent with the well-known impaired insulin sensitivity in Tg mice over-expressing GH.

One should emphasize that mTOR may integrate and coordinate various extracellular signals (Mamane et al. 2006). Importantly, reduced expression of genes associated with the mTOR signaling pathway has been shown in individuals from long-lived families in the Leiden Longevity Study (Slagboom et al. 2011). Therefore, increased total mTOR levels in short-lived Tg mice, as observed by us, may suggest an important role of TOR signaling in lifespan regulation. Also, increased phosphorylated mTOR protein levels in Tg mice in comparison with $\mathrm{N}$ animals may confirm this relevant observation.

Presumably, the decrease in AKT2, an enzyme involved in PI3K/AKT/mTOR signaling, can also be viewed as beneficial. This hypothesis could be confirmed by the observation that AKT2 is the major isoform shown to be over-expressed in cancer in humans (reviewed by Hers et al. (2011)). On the other hand, Garofalo et al. (2003) have unexpectedly shown that AKT2-deficient mice are insulin-resistant with the tendency to development of diabetes in males. Therefore, the role of AKT2 in insulin sensitivity regulation requires further analysis.

Interestingly, the differences in insulin levels were no longer present between normal and Tg mice without PIO treatment after the treatment period (when compared with the beginning of the study). This could have been caused by the method of blood collection used. Initially, the blood was collected by orbital bleeding after brief isoflurane anesthetic while the final collection was performed after ketamine/xylosine anesthesia with cardiac bleeding. Therefore, these two different methods of blood collection (differently stimulating the stress of the animals) could cause the difference in insulin values after the treatment period when comparing $\mathrm{N}$ and $\mathrm{Tg}$ animals.

In summary, absence of effects of PIO treatment in Tg mice over-expressing $\mathrm{GH}$ suggest that chronically increased GH level may inhibit the beneficial effects of PIO on the insulin signaling pathway. In contrast, PIO improved insulin signaling in animals with normal $\mathrm{GH}$ levels. Therefore, one might suggest that PIO may not be useful in the management of impaired glucose tolerance

Published by Bioscientifica Ltd 
or type 2 diabetes in patients with elevated GH levels. Presumably, higher doses of PIO would be required to exert beneficial effects on insulin signaling under conditions of GH overproduction. Further studies are needed to determine the therapeutic possibilities of PIO and explain how this anti-diabetic drug may exert beneficial effects.

\section{Declaration of interest}

The authors declare that there is no conflict of interest that could be perceived as prejudicing the impartiality of the research reported.

\section{Funding}

This study is supported by Takeda Pharmaceuticals USA, Inc. This study was also supported by the NIA, AG032290, AG 19899, AG031736, and U19 AG023122, Polish National Science Centre (DEC-2012/04/M/NZ4/00198) (grant no. 507/1-107-05/507-10-050 of the Medical University of Lodz, Poland), and Polish Ministry of Science and Higher Education (N N401 042638).

\section{References}

Abegunde DO, Mathers CD, Adam T, Ortegon M \& Strong K 2007 The burden and costs of chronic diseases in low-income and middle-income countries. Lancet 370 1929-1938. (doi:10.1016/ S0140-6736(07)61696-1)

Anisimov VN, Zabezhinski MA, Popovich IG, Piskunova TS, Semenchenko AV, Tyndyk ML, Yurova MN, Rosenfeld SV \& Blagosklonny MV 2011 Rapamycin increases lifespan and inhibits spontaneous tumorigenesis in inbred female mice. Cell Cycle $\mathbf{1 0} 4230-4236$. (doi:10.4161/cc.10.24. 18486)

Bartke A 2003 Can growth hormone (GH) accelerate aging? Evidence from GH transgenic mice Neuroendocrinology 78 210-216. (doi:10.1159/ 000073704)

Bjedov I, Toivonen JM, Kerr F, Slack C, Jacobson J, Foley A \& Partridge L 2010 Mechanisms of life span extension by rapamycin in the fruit fly Drosophila melanogaster. Cell Metabolism 11 35-46. (doi:10.1016/j.cmet. 2009.11.010)

Coelho M, Oliveira T \& Fernandes R 2013 Biochemistry of adipose tissue: an endocrine organ. Archives of Medical Science 9 191-200. (doi:10.5114/ aoms.2013.33181)

Davidson MB 1987 Effect of growth hormone on carbohydrate and lipid metabolism. Endocrine Reviews 8 115-131. (doi:10.1210/edrv-8-2-115)

Elte JW \& Blickle JF 2007 Thiazolidinediones for the treatment of type 2 diabetes. European Journal of Internal Medicine 18 18-25. (doi:10.1016/ j.ejim.2006.09.007)

Fried SK, Bunkin DA \& Greenberg AS 1998 Omental and subcutaneous adipose tissues of obese subjects release interleukin-6: depot difference and regulation by glucocorticoid. Journal of Clinical Endocrinology and Metabolism 83 847-850. (doi:10.1210/jc.83.3.847)

Garofalo RS, Orena SJ, Rafidi K, Torchia AJ, Stock JL, Hildebrandt AL, Coskran T, Black SC, Brees DJ, Wicks JR et al. 2003 Severe diabetes, age-dependent loss of adipose tissue, and mild growth deficiency in mice lacking Akt2/PKBß. Journal of Clinical Investigation 112 197-208. (doi:10.1172/JCI16885)

Gesing A, Masternak MM, Wang F, Joseph AM, Leeuwenburgh C, Westbrook R, Lewinski A, Karbownik-Lewinska M \& Bartke A 2011 Expression of key regulators of mitochondrial biogenesis in growth hormone receptor knockout (GHRKO) mice is enhanced but is not further improved by other potential life-extending interventions. Journals of Gerontology. Series A: Biological Sciences and Medical Sciences 66 1062-1076. (doi:10.1093/gerona/glr080)

Gong Y, Li J, Li C, Mu Y, Xiao Y, Tian H, Pan C \& Liu Y 2012 The adipose tissue endocrine mechanism of the prophylactic protective effect of pioglitazone in high-fat diet-induced insulin resistance. Journal of International Medical Research 40 1304-1316. (doi:10.1177/ 147323001204000409)

Hansen I, Tsalikian E, Beaufrere B, Gerich J, Haymond M \& Rizza R 1986 Insulin resistance in acromegaly: defects in both hepatic and extrahepatic insulin action. American Journal of Physiology 250 E269-E273.

Hers I, Vincent EE \& Tavare JM 2011 Akt signalling in health and disease. Cellular Signalling 23 1515-1527. (doi:10.1016/j.cellsig.2011.05.004)

Holdaway IM, Rajasoorya RC \& Gamble GD 2004 Factors influencing mortality in acromegaly. Journal of Clinical Endocrinology and Metabolism 89 667-674. (doi:10.1210/jc.2003-031199)

Jamieson E, Chong MM, Steinberg GR, Jovanovska V, Fam BC, Bullen DV, Chen Y, Kemp BE, Proietto J, Kay TW et al. 2005 Socs1 deficiency enhances hepatic insulin signaling. Journal of Biological Chemistry 280 31516-31521. (doi:10.1074/jbc.M502163200)

Jiang LQ, Duque-Guimaraes DE, Machado UF, Zierath JR \& Krook A 2013 Altered response of skeletal muscle to IL-6 in type 2 diabetic patients. Diabetes 62 355-361. (doi:10.2337/db11-1790)

Kanatani Y, Usui I, Ishizuka K, Bukhari A, Fujisaka S, Urakaze M, Haruta T, Kishimoto T, Naka T \& Kobayashi M 2007 Effects of pioglitazone on suppressor of cytokine signaling 3 expression: potential mechanisms for its effects on insulin sensitivity and adiponectin expression. Diabetes 56 795-803. (doi:10.2337/db06-1039)

Kim DD, Goh J, Panossian Z, Gamble G, Holdaway I \& Grey A 2012 Pioglitazone in acromegaly - an open-label, prospective study. Clinical Endocrinology 77 575-578. (doi:10.1111/j.1365-2265.2012.04411.x)

Kopchick JJ, Bellush LL \& Coschigano KT 1999 Transgenic models of growth hormone action. Annual Review of Nutrition 19 437-461. (doi:10.1146/annurev.nutr.19.1.437)

Krag MB, Nielsen S, Guo Z, Pedersen SB, Schmitz O, Christiansen JS \& Jorgensen JO 2008 Peroxisome proliferator-activated receptor $\gamma$ agonism modifies the effects of growth hormone on lipolysis and insulin sensitivity. Clinical Endocrinology 69 452-461. (doi:10.1111/ j.1365-2265.2008.03231.x)

Krag MB, Rasmussen LM, Hansen TK, Frystyk J, Flyvbjerg A, Moller N \& Jorgensen JO 2009 Peroxisome proliferator-activated receptor gamma (PPAR) agonism reduces the insulin-stimulated increase in circulating interleukin-6 in GH replaced GH-deficient adults. Clinical Endocrinology 71 363-368. (doi:10.1111/j.1365-2265.2008.03483.x)

Kucia M, Masternak M, Liu R, Shin DM, Ratajczak J, Mierzejewska K, Spong A, Kopchick JJ, Bartke A \& Ratajczak MZ 2013 The negative effect of prolonged somatotrophic/insulin signaling on an adult bone marrowresiding population of pluripotent very small embryonic-like stem cells (VSELs). Age 35 315-330. (doi:10.1007/s11357-011-9364-8)

Li P, Shibata R, Unno K, Shimano M, Furukawa M, Ohashi T, Cheng X, Nagata K, Ouchi N \& Murohara T 2010 Evidence for the importance of adiponectin in the cardioprotective effects of pioglitazone. Hypertension 55 69-75. (doi:10.1161/HYPERTENSIONAHA.109.141655)

Lincoff AM, Wolski K, Nicholls SJ \& Nissen SE 2007 Pioglitazone and risk of cardiovascular events in patients with type 2 diabetes mellitus: a metaanalysis of randomized trials. Journal of the American Medical Association 298 1180-1188. (doi:10.1001/jama.298.10.1180)

Mamane Y, Petroulakis E, LeBacquer O \& Sonenberg N 2006 mTOR, translation initiation and cancer. Oncogene 25 6416-6422. (doi:10.1038/sj.onc.1209888)

McGrane MM, de Vente J, Yun J, Bloom J, Park E, Wynshaw-Boris A, Wagner T, Rottman FM \& Hanson RW 1988 Tissue-specific expression and dietary regulation of a chimeric phosphoenolpyruvate carboxykinase/bovine growth hormone gene in transgenic mice. Journal of Biological Chemistry 263 11443-11451. 
Miller RA, Harrison DE, Astle CM, Baur JA, Boyd AR, de Cabo R, Fernandez E, Flurkey K, Javors MA, Nelson JF et al. 2011 Rapamycin, but not resveratrol or simvastatin, extends life span of genetically heterogeneous mice. Journals of Gerontology. Series A: Biological Sciences and Medical Sciences 66 191-201. (doi:10.1093/gerona/glq178)

Nawrocki AR, Rajala MW, Tomas E, Pajvani UB, Saha AK, Trumbauer ME, Pang Z, Chen AS, Ruderman NB, Chen H et al. 2006 Mice lacking adiponectin show decreased hepatic insulin sensitivity and reduced responsiveness to peroxisome proliferator-activated receptor gamma agonists. Journal of Biological Chemistry 281 2654-2660. (doi:10.1074/ jbc.M505311200)

Pedersen BK \& Febbraio MA 2008 Muscle as an endocrine organ: focus on muscle-derived interleukin-6. Physiological Reviews 88 1379-1406. (doi:10.1152/physrev.90100.2007)

Powell LA, Crowe P, Kankara C, McPeake J, McCance DR, Young IS, Trimble ER \& McGinty A 2012 Restoration of adipose function in obese glucose-tolerant men following pioglitazone treatment is associated with CCAAT enhancer-binding protein $\beta$ up-regulation. Clinical Science 123 135-146. (doi:10.1042/CS20110662)

Puddu A, Sanguineti R, Durante A \& Viviani GL 2012 Pioglitazone attenuates the detrimental effects of advanced glycation end-products in the pancreatic beta cell line HIT-T15. Regulatory Peptides 177 79-84. (doi:10.1016/j.regpep.2012.05.089)

Russell-Jones D, Cuddihy RM, Hanefeld M, Kumar A, Gonzalez JG, Chan M, Wolka AM, Boardman MK \& DURATION-4 Study Group 2012 Efficacy and safety of exenatide once weekly versus metformin, pioglitazone, and sitagliptin used as monotherapy in drug-naïve patients with type 2 diabetes (DURATION-4): a 26-week double-blind study. Diabetes Care 35 252-258. (doi:10.2337/dc11-1107)

Saremi A, Schwenke DC, Buchanan TA, Hodis HN, Mack WJ, Banerji M, Bray GA, Clement SC, Henry RR, Kitabchi AE et al. 2013 Pioglitazone slows progression of atherosclerosis in prediabetes independent of changes in cardiovascular risk factors. Arteriosclerosis, Thrombosis, and Vascular Biology 33 393-399. (doi:10.1161/ATVBAHA.112.300346)

Schaalan MF 2012 Effects of pioglitazone and/or simvastatin on circulating $\mathrm{TNF} \alpha$ and adiponectin levels in insulin resistance. Journal of Immunotoxicology 9 201-209. (doi:10.3109/1547691X.2012.660998)
Selman C \& Partridge L 2012 A double whammy for aging? Rapamycin extends lifespan and inhibits cancer in inbred female mice Cell Cycle 11 17-18. (doi:10.4161/cc.11.1.18736)

Slagboom PE, Beekman M, Passtoors WM, Deelen J, Vaarhorst AA, Boer JM, van den Akker EB, van Heemst D, de Craen AJ, Maier AB et al. 2011 Genomics of human longevity. Philosophical Transactions of the Royal Society B: Biological Sciences 366 35-42. (doi:10.1098/rstb.2010.0284)

Taniguchi CM, Tran TT, Kondo T, Luo J, Ueki K, Cantley LC \& Kahn CR 2006 Phosphoinositide 3-kinase regulatory subunit p85 $\alpha$ suppresses insulin action via positive regulation of PTEN. PNAS 103 12093-12097. (doi:10.1073/pnas.0604628103)

Ueki K, Kondo T \& Kahn CR 2004 Suppressor of cytokine signaling 1 (SOCS-1) and SOCS-3 cause insulin resistance through inhibition of tyrosine phosphorylation of insulin receptor substrate proteins by discrete mechanisms. Molecular and Cellular Biology 24 5434-5446. (doi:10.1128/MCB.24.12.5434-5446.2004)

Wan Z, Ritchie I, Beaudoin MS, Castellani L, Chan CB \& Wright DC $2012 a$ IL-6 indirectly modulates the induction of glyceroneogenic enzymes in adipose tissue during exercise. PLoS ONE 7 e41719. (doi:10.1371/ journal.pone.0041719)

Wan Z, Perry CG, Macdonald T, Chan CB, Holloway GP \& Wright DC $2012 b$ IL-6 is not necessary for the regulation of adipose tissue mitochondrial content. PLOS ONE 7 e51233. (doi:10.1371/journal. pone.0051233)

Wang Z, Masternak MM, Al-Regaiey KA \& Bartke A 2007 Adipocytokines and the regulation of lipid metabolism in growth hormone transgenic and calorie-restricted mice. Endocrinology 148 2845-2853. (doi:10.1210/en.2006-1313)

Wilkinson JE, Burmeister L, Brooks SV, Chan CC, Friedline S, Harrison DE, Hejtmancik JF, Nadon N, Strong R, Wood LK et al. 2012 Rapamycin slows aging in mice. Aging Cell 11 675-682. (doi:10.1111/j.1474-9726. 2012.00832.x)

Yu JG, Javorschi S, Hevener AL, Kruszynska YT, Norman RA, Sinha M \& Olefsky JM 2002 The effect of thiazolidinediones on plasma adiponectin levels in normal, obese, and type 2 diabetic subjects. Diabetes 51 2968-2974. (doi:10.2337/diabetes.51.10.2968)

Received in final form 26 July 2013

Accepted 14 August 2013

Accepted Preprint published online 14 August 2013
() 2013 Society for Endocrinology Printed in Great Britain 